\title{
PERFIL E LUGAR DOS ARQUIVOS PRIVADOS INSTITUCIONAIS EM ENTIDADES CUSTODIADORAS CARIOCAS
}

\section{THE PROFILES AND THE PLACE OF THE PRIVATE INSTITUTIONAL ARCHIVES IN ARCHIVAL CUSTODY ENTITIES OF THE CITY OF RIO DE JANEIRO}

\author{
Gabriela Ayres Ferreira Terradaa \\ Vitor Manoel Marques da Fonsecab
}

\begin{abstract}
RESUMO
Introdução: A ausência de reflexão na área arquivística sobre arquivos privados de entidades coletivas impõe do estudo de "seu lugar" no atual contexto brasileiro e nas entidades de guarda e preservação da memória nacional. Objetivo: Investigar o perfil e o lugar dos arquivos privados de entidades coletivas em entidades custodiadoras de acervo arquivístico da cidade do Rio de Janeiro. Metodologia: Pesquisa exploratória e descritiva sobre o perfil e o lugar desses arquivos com base nas instituições cariocas presentes no Cadastro Nacional de Entidades Custodiadoras de Acervos Arquivísticos com sites e guias online, para quantificar e identificar os arquivos privados de entidades coletivas custodiados. Resultados: Análise dos arquivos de entidades coletivas privadas custodiados face ao número de arquivos privados pessoais, as características que possuem e a sua categorização em termos temáticos e de atividades desempenhadas por seus produtores. Conclusões: Fraca presença de arquivos de entidades coletivas privadas nas instituições de memória cariocas, inexistência de políticas de aquisição para esse tipo de acervos e risco de graves lacunas no patrimônio documental nacional.
\end{abstract}

Descritores: Arquivos Privados. Arquivos privados de entidades coletivas. Arquivo permanente. Patrimônio documental.

a Bibliotecária na Fundação Biblioteca Nacional, BNDigital. E-mail: gaby.uff@gmail.com

b Doutor em História pela Universidade Federal Fluminense. Professor do Departamento de Ciência da Informação da Universidade Federal Fluminense. E-mail: vitormowlac@gmail.com 


\section{INTRODUÇÃO}

Os arquivos têm como atribuições básicas "a gestão, a guarda e a difusão das informações contidas nos documentos produzidos, recebidos ou acumulados pelas diferentes entidades públicas ou privadas no decorrer de sua vida ativa" (BELLOTTO, 2014, p. 133). Por isso, são também instituições de memória, devendo "[...] preservar e fornecer acesso às provas de ações e decisões passadas" (EASTWOOD; MACNEIL, 2017, p. 237).

O Brasil dispõe de uma lei que trata dos arquivos públicos e privados, a chamada Lei de Arquivos (lei $n^{\circ} 8.159$, de 8 de janeiro de 1991). Todavia, a referida lei, quanto aos arquivos privados, refere-se somente àqueles que, por ato presidencial, são declarados de "interesse público e social". O futuro daqueles que não são assim declarados é incerto, pela inexistência de disposições jurídicas específicas nem políticas voltadas à sua preservação.

A literatura arquivística mais recente deu um maior enfoque aos arquivos pessoais e ao "seu lugar" dentro das instituições de memória - com as "relações clássicas entre história, memória e arquivo, o tema ganha relevância no contexto dos recentes debates sobre 'culto à memória' e [os seus] usos" (HEYMANN, 2012, p. 17). No entanto, os arquivos privados de entidades coletivas não recebem a mesma atenção e permanecem pouco estudados.

A necessidade de entender a ausência do tema arquivos privados de entidades coletivas levou-nos a estudar o "seu lugar" no atual contexto arquivístico brasileiro e nas entidades de guarda e preservação da memória nacional. Consideramos o problema relevante, uma vez que nos parece inconteste que tais arquivos também são parte importante na construção da memória e do patrimônio nacional.

Vitoriano $(2016,2017)$ torna evidente a importância de analisar o lugar dos arquivos privados de entidades coletivas dentro das instituições de memória. Estimulados por suas ideias, optamos por estudar o perfil dos arquivos de entidades coletivas privadas em instituições de memória da cidade do Rio de Janeiro, com o propósito de responder aos seguintes questionamentos: Quais são esses arquivos e onde eles estão? Há algo em 
comum entre os que estão disponíveis para acesso público?

Após a revisão de literatura, foram levantadas as instituições da cidade do Rio de Janeiro inscritas no Cadastro Nacional de Entidades Custodiadoras de Acervos Arquivísticos (CODEARQ) - o qual identifica as entidades com acervo arquivístico no Brasil, através de codificação obtida no preenchimento de formulário no site do Conselho Nacional de Arquivos (CONARQ) - a fim de verificar se as mesmas custodiavam acervos privados, e possuíam instrumento de pesquisa disponível para consulta através de website. A escolha da cidade do Rio de Janeiro se justifica pelo fato de a mesma sediar grandes e importantes instituições (inclusive as mais antigas no país) que custodiam acervos arquivísticos - no CODEARQ, o Estado do Rio de Janeiro é o que detém o maior número de entidades, em sua maioria, localizadas na Capital.

A partir dos resultados obtidos na análise dos conjuntos documentais encontrados, foram investigados os perfis desses conjuntos e de seus produtores, quantificados os arquivos custodiados e seus produtores foram qualificados e categorizados, conforme o Código Civil Brasileiro e autores como Marquant (1960) Pazin (2005; 2012) e Bellotto (2006), além de serem classificados em relação à Classificação Nacional de Atividades Econômicas (CNAE), disponibilizada pelo Instituto Brasileiro de Geografia e Estatística (IBGE).

\section{ARQUIVOS PÚBLICOS E ARQUIVOLOGIA}

A reflexão teórica sobre arquivos, na maior parte do tempo, baseou-se na experiência da lida com arquivos públicos, ou seja, numa concepção estrita, com conjuntos de documentos produzidos e acumulados por órgãos públicos. Pode-se considerar que arquivos privados, ao serem doados a instituições arquivísticas públicas, passam a ser públicos, pois são incorporados ao patrimônio público. No entanto, neste texto, trabalhamos com a ideia de público e privado a partir da acumulação e produção, não em termos de propriedade.

O fato da reflexão teórica voltar-se para arquivos públicos tem sua origem na própria história dos arquivos. No Manual dos arquivistas holandeses, obra fundante na área, a definição de arquivo é bem restrita: 
Arquivo é o conjunto de documentos escritos, desenhos e material impresso, recebidos ou produzidos oficialmente por determinado órgão administrativo ou por um de seus profissionais, na medida em que tais documentos se destinavam a permanecer na custódia desse órgão ou funcionário (ASSOCIAÇÃO DOS ARQUIVISTAS HOLANDESES, 1973, p. 13; grifo no original).

Segundo essa definição, a ideia de arquivo está ligada única e exclusivamente a órgãos administrativos, ou seja, a unidades integrantes da máquina pública e estatal. Tal obra, mais à frente, reconhece que "órgãos administrativos e empregados de entidades privadas também podem originar um arquivo" (ASSOCIAÇÃO DOS ARQUIVISTAS HOLANDESES, 1973, p. 19), mas não admite a existência de arquivos de famílias e é lacônica sobre arquivos de pessoas, ligando-os à documentação de empresas que dirijam (idem). De fato, o grande foco de sua reflexão são os arquivos públicos.

Hoje, a palavra arquivo é polissêmica. No Dicionário de Terminologia Arquivística (2005, p. 27; 96), existem as seguintes acepções:

- Conjunto de documentos produzidos e acumulados por uma entidade coletiva, pública ou privada, pessoa ou família, no desempenho de suas atividades, independentemente da natureza do suporte;

- Fundo que é um conjunto de documentos de uma mesma proveniência;

- Instituição ou serviço que tem por finalidade a custódia, processamento técnico, conservação e o acesso a documentos;

- Instalações onde funcionam arquivos, [isto é, o local propriamente dito];

- Móvel destinado à guarda de documentos.

Rousseau e Couture (1998) afirmam que foi no século XIX que surgiu o "interesse por outros tipos de arquivos para além dos arquivos governamentais, os arquivos privados: arquivos econômicos, arquivos de igrejas, arquivos sociais" (ROUSSEAU; COUTURE, 1998, p. 42). Os autores ressaltam ainda que "os arquivos de notáveis, de homens de negócios, de família são considerados como arquivos privados", e que os mesmos se fazem necessários tanto aos seus produtores como ao poder público (ROUSSEAU; COUTURE, 1998, p. 37).

Os arquivos eram tradicionalmente criados pelo Estado, para 
servir ao Estado, como parte da estrutura hierárquica e da cultura organizacional do Estado. Assim, a teoria, os princípios e as metodologias arquivísticas popularizadas ao redor do mundo por esses autores pioneiros (e por seus inúmeros seguidores) refletiram de modo nada surpreendente a natureza inerente dos documentos governamentais e de seus criadores institucionais oficiais, com os quais os autores estavam intimamente familiarizados. (COOK, 1998, p. 133).

Se a práxis da Arquivologia "está intimamente ligada à existência dos arquivos" e a mesma "desenvolveu-se em função das necessidades de cada época" (ROUSSEAU; COUTURE, 1998, p. 48), também importa ter claro que a teorização que vai determinar essa prática esteve sempre condicionada pelo fato de se basear na experiência e na reflexão ligada à documentação pública - a arquivos públicos.

\section{ARQUIVOS PRIVADOS}

Os arquivos privados são classificados em pessoais e institucionais e, segundo Heymann (1997, p. 42), para obter entendimento da definição de arquivo privado, é preciso saber que "a unidade de cada um deles é conferida pela pessoa ou instituição que o constituiu, ou seja, por quem acumulou determinados documentos dentro do universo daqueles produzidos e recebidos". "Ao contrário dos institucionais, os arquivos pessoais não possuem qualquer estrutura indicando que certos documentos foram ou deveriam ter sido criados/preservados" e que estão "numa curiosa posição, ao mesmo tempo dentro e fora do desenvolvimento do pensamento arquivístico" (EASTWOOD; MACNEIL, 2017, p. 303-2).

$\mathrm{Na}$ teoria arquivística clássica, os arquivos públicos ou privados de entidades coletivas "[...] são apresentados como acumulações naturais, orgânicas, inocentes, transparentes que os arquivistas preservam de modo imparcial, neutro e objetivo", e os arquivos pessoais "[...] como mais artificiais, antinaturais, arbitrários" (COOK, 1998, p. 131).

Como já mencionado, o termo arquivo é polissêmico. Sendo assim, as suas segmentações - os arquivos privados, por exemplo, receberam diversas acepções. Bellotto (1978, p. 5) usou o termo arquivos particulares - "[...] 
documentos produzidos ou recebidos por entidade particular ou pessoa, no decurso de suas atividades, formando um conjunto orgânico e preservado para informação administrativa, jurídica ou histórica”. Já Schellenberg (2006, p. 269270) fala dos papeis conhecidos como 'manuscritos históricos' - originários de famílias, comumente organizados pelos bibliotecários e custodiados nas bibliotecas. $\mathrm{O}$ autor diz que manuscrito é termo mais limitado, e usa para arquivos privados a expressão "papeis privados - que inclui material que se origina de uma pessoa quanto de uma entidade". O Dicionário de Terminologia Arquivística define arquivo privado como "Arquivo (1) de entidade coletiva de direito privado, família ou pessoa. Também chamado arquivo particular" (ARQUIVO NACIONAL, 2005, p. 35).

Bellotto (2006, p. 251) dividiu os arquivos privados, gerados por instituições não governamentais ou produzidos por famílias ou indivíduos, em três tipos: econômicos, sociais e pessoais. Segundo a autora (BELLOTTO, 2006, p. 254-257):

- Arquivos econômicos - são gerados por empresas comerciais, industriais, financeiras ou serviços, como exemplo: os bancos, seguradoras, empresas agrícolas, transporte etc;

- Arquivos sociais - são os religiosos, notariais e os de movimentos e entidades políticas, como exemplo a documentação de instituições educacionais privadas e de associações de classe, esportivas, beneficentes e culturais;

- Arquivos pessoais - papéis produzidos/recebidos por entidades ou pessoas físicas (família) de direito privado, ligados à vida e a obra e às atividades de uma pessoa, como a vida familiar, civil, profissional e a produção política/intelectual/cientifica/artística (BELLOTTO, 2006, p. 254257).

Dos três tipos acima, os econômicos e os sociais são ligados a entidades coletivas, que podem ou não ser pessoas jurídicas, ao passo que os arquivos pessoais são referentes a uma pessoa física ou família. Paes (2004, p. 21) também divide os "[...] arquivos privados em três tipos: institucionais (instituições educacionais, igrejas, corporações não lucrativas, sociedades e associações)", equivalentes aos arquivos sociais citados acima, e "arquivos comerciais (firmas, corporações, companhias)" equiparados aos arquivos econômicos. Marquant (1960) utiliza a nomenclatura de arquivos econômicos e 
sociais. O autor estudou os arquivos privados na "organização dos serviços econômicos e sociais em diferentes países, no âmbito público e privado, científicos, comerciais, sindicais e de empresas" (MARQUANT, 1960, p. 5).

Diferenciar os arquivos privados não é uma tarefa fácil, pois cada autor tem uma visão distinta para o mesmo tipo de arquivo. "Do ponto de vista arquivístico, tais enfoques ganham especial relevância por contribuírem para o estabelecimento de tipos que circulam fora do ambiente estritamente estatal" (CAMARGO, 2009, p. 35). De acordo com Célia Camargo (2003), no Brasil na década de 1970, houve "tanto na esfera privada quanto na pública", esforços no sentido de organizar e proteger o patrimônio documental, ações que demonstram "um intenso movimento em torno da questão cultural e da memória nacional" (CAMARGO, 2003, p. 24). Assim, a preocupação com os arquivos privados no Brasil foi impulsionada pela valorização dos espaços de memória e de custódia de acervo documental.

$\mathrm{O}$ acesso a arquivos privados é um grande problema, devido ao término das atividades do produtor e, muitas vezes, pelo fato de seus documentos não serem custodiados em instituições públicas, onde seu acesso seria franqueado (BELLOTTO, 1978; BASTOS, 1981; VITORIANO, 2017). "Considerando os arquivos privados, especialmente aqueles de origem institucional, a preservação do acervo significa, na maior parte das vezes, garantir sua sobrevivência após o desaparecimento da entidade que o produziu" (VITORIANO, 2016, p. 12). No caso dos arquivos pessoais, "[...] muitas vezes este fundo é percebido pelos familiares como parte da herança" (VITORIANO, 2017 , p. 2), podendo ser custodiado pela própria família ou enviado para uma instituição de memória. Marquant (1960, p. 7) também discute o problema de acesso aos arquivos privados institucionais, afirmando que "[...] na maioria dos países de regime econômico capitalista os papéis das empresas privadas não são recolhidos", ou seja, os arquivos privados ficam custodiados pelos seus produtores e não pelas instituições arquivísticas.

Os arquivos servem para contar a história e resguardar a memória da humanidade, por isso torna-se primordial preservá-los. Deste modo, faz-se necessário um estudo para identificar e mensurar "o lugar" dos arquivos 
privados institucionais/de entidades coletivas nas instituições de guarda e preservação, visto que os mesmos também guardam a memória da sociedade onde estão inseridos e sua perda repercute diretamente no patrimônio memorial social. Sua preservação e o acesso ao público deveriam ser efetuados pelas próprias entidades que os produziram ou por instituições arquivísticas públicas.

\section{ARQUIVOS PÚBLICOS E PRIVADOS E NA LEGISLAÇÃO ARQUÍSTICA BRASILEIRA}

Segundo Lafer (2005, p. 34), a ideia do que é público corresponde ao que é comum a toda sociedade, enquanto o privado é considerado o que não é comum a todos, mas sim particular a alguns, tido como reservado e pessoal. Entrando no universo dos arquivos e suas categorias, percebemos que arquivo, por um longo tempo, foi considerado apenas aquele conjunto documental de origem pública; no entanto, arquivos públicos ou privados fazem parte do patrimônio brasileiro. Bastos e Araújo (1990, p. 24) afirmam que, a partir do artigo 216 da Constituição Federal de 1988, iniciou-se o movimento de proteção documental em nível nacional:

Constituem patrimônio cultural brasileiro os bens de natureza material e imaterial, tomados individualmente ou em conjunto, portadores de referência à identidade, à ação, à memória dos diferentes grupos formadores da sociedade brasileira (BRASIL, 1988).

A lei n. 8.159/1991 ampliou a visão do valor social e histórico dos documentos, e consequentemente a percepção da importância dos arquivos privados, e respaldou o aumento da utilização dos arquivos privado. Tal lei, juntamente com a resolução $n^{\circ}$ 3/1995 do CONARQ "que promove assessoria técnica e metodológica aos arquivos públicos e privados", e que ressalta a sentença "interesse público social" através dos resultados esperados de sua aplicação, propiciaram a "[...] reflexão para a patrimonialização dos arquivos privados em instituições de preservação e salvaguarda de bens culturais" (MOLINA, 2013, p. 161).

Ainda que a legislação em nosso país sugira uma preocupação com a 
preservação dos arquivos privados, isto não configura uma obrigatoriedade (CAMPOS, 2016, p. 7). Conforme o art. 22, primeiro parágrafo da lei $n^{\circ} 8.159$, quando o arquivo é declarado de interesse público e social, não é obrigatório seu remanejamento para "instituição arquivística pública, nem exclui a responsabilidade por parte de seus detentores pela guarda e preservação do acervo" (BRASIL, 1991). Mais ainda, não há obrigatoriedade de acesso público a esses arquivos.

No segundo parágrafo, são frisados os "arquivos que são declarados automaticamente de interesse público e social" e o inciso II trata dos "arquivos presidenciais", apoiando-se na lei $n^{\circ}$ 8.394, 30 de dezembro de 1991, que "dispõe sobre a preservação, organização e proteção dos acervos documentais privados dos presidentes da República e dá outras providências". Outro dispositivo de patrimonialização é a resolução $n^{\circ}$ 17, de 25 de julho de 2003, do CONARQ, que "Dispõe sobre os procedimentos relativos à declaração de interesse público e social de arquivos privados de pessoas físicas ou jurídicas que contenham documentos relevantes para a história, a cultura e o desenvolvimento nacional".

Apesar de o Brasil ter uma legislação que ampara a preservação e a guarda de arquivos privados de interesse público e social, ainda não temos um número expressivo de arquivos assim considerados. Ao analisarmos os quatorze arquivos declarados de interesse público e social, observamos que apenas cinco são de entidades coletivas (pessoas jurídicas ou não), equivalendo a $35,71 \%$ do total dos arquivos que receberam tal distinção, enquanto os de origem pessoal perfazem os demais $64,29 \%$. Cabe, porém, registrar que, sem necessitarem de decreto específico, são também de interesse público e social os arquivos presidenciais e os registros civis de arquivos, anteriores ao Código Civil, de entidades religiosas (BRASIL, 1991).

\section{ARQUIVOS PRIVADOS INSTITUCIONAIS NAS ENTIDADES ARQUIVÍSTICAS CARIOCAS}

Para a seleção das entidades arquivísticas cariocas recorreu-se, no período de 23 de abril a 7 de maio 2017, ao CODEARQ. Foram encontradas no 
estado do Rio de Janeiro 62 entidades. Desse total, a cidade do Rio de Janeiro concentra $79 \%$, estando os outros $21 \%$ no interior. Daquelas existentes na capital, apenas $22 \%$ dispunham de instrumentos de pesquisa online.

Ao investigar cada instrumento de pesquisa, estabelecemos, então, as sete entidades custodiadoras em que aprofundaríamos nossa pesquisa, a fim de explorar os seus arquivos privados e posteriormente classificá-los quanto à origem, natureza e o conteúdo. Fizeram parte da presente pesquisa o Arquivo Geral da Cidade do Rio de Janeiro (AGCRJ), o Arquivo Nacional (AN), o Arquivo-Museu de Literatura Brasileira (AMLB), a Casa de Oswaldo Cruz (COC), o Centro de Pesquisa e Documentação de História Contemporânea do Brasil (CPDOC), a Fundação Biblioteca Nacional (FBN) e o Instituto Histórico e Geográfico Brasileiro (IHGB). No entanto, o IHGB não dispõe de arquivos de entidades coletivas privadas, apenas detém arquivos pessoais.

Nesse conjunto, há entidades custodiadoras privadas e públicas, de âmbito municipal, federal e privado, ligadas à cultura, à saúde, à história, à geografia, às ciências sócias e à cidadania e segurança (Ministério da Justiça). Algumas delas têm representação no Comitê Brasileiro do Programa Memória do Mundo da UNESCO, que visa a estimular a proteção e a preservação do patrimônio documental da humanidade, e têm acervos inscritos no mesmo Programa.

Do universo de 1737 conjuntos documentais que custodiam, 665 são de entidades coletivas públicas, 900 são arquivos pessoais, 110 são coleções temáticas/sem identificação de produtores e apenas 62 são arquivos de entidades coletivas privadas.

O percentual dos arquivos pessoais em relação aos arquivos de entidades privadas é sumamente maior. De acordo com Estevão e Fonseca (2010), o recebimento de "documentos de família já era prática definida pelo Arquivo Nacional desde 1888". Talvez seja este um dos motivos do grande volume de arquivos privados pessoais presentes no AN e nas outras entidades de memória.

Foram encontrados no âmbito dos arquivos privados, 62 de entidades coletivas privadas e 900 pessoais. Ou seja, cerca de $52 \%$ do total de acervos 
custodiados são arquivos pessoais e apenas $4 \%$ são arquivos de entidades coletivas privadas. O Arquivo Nacional, a mais antiga instituição arquivística do Brasil, detém o maior número de acervos de entidades coletivas privadas (71\%) dentre as instituições pesquisadas, sendo seguido pelo CPDOC, a única entidade custodiadora privada de nosso recorte final, com (13\%), da FBN (8\%), da COC e do AGCRJ (3\% cada um) e da AMLB (2\%).

\section{Gráfico 1- Total de Fundos das Entidades Coletivas Privadas}

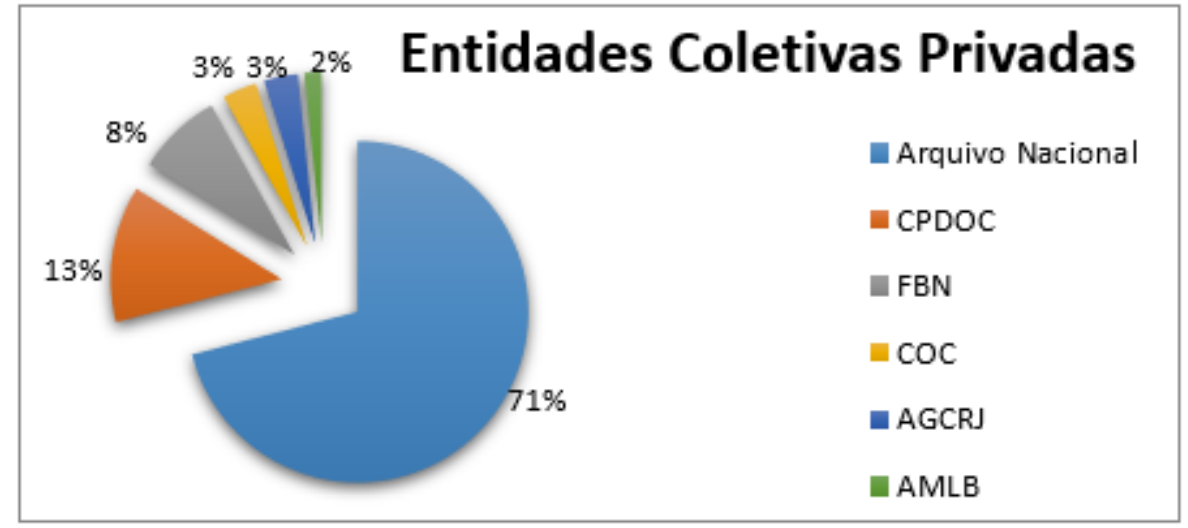

Fonte: Dados da pesquisa

Os dados revelam a importância da pesquisa sobre entidades coletivas privadas presentes nas instituições de memória, pelo fato de podermos recuperar através dos documentos, sejam eles de origem pública ou privada, parte de nossa história. Portanto faz-se necessário traçar o perfil das entidades coletivas privadas cujos acervos são custodiados pelas instituições cariocas.

Para traçar o perfil dos 62 arquivos e os tipos de entidades coletivas privadas que os produziram, os dividimos e categorizamos conforme sua história administrativa, com apoio da CNAE, disponibilizada pelo IBGE. Observamos que as entidades analisadas estavam presentes nas dez grandes áreas: (1) indústrias de transformação; (2) construção; (3) comércio varejista; (4) informação e comunicação; (5) atividades financeiras, de seguros e serviços; (6) atividades profissionais, científicas e técnicas; (7) saúde humana e serviços sociais; (8) artes, cultura, esporte e recreação; (9) outras atividades de serviços; (10) organismos internacionais e outras instituições extraterritoriais. Classificamos os arquivos de entidades coletivas privadas como provenientes das seguintes categorias: Sociedades Empresariais (29), Associações (21), 
Organizações Religiosas (2), Agremiações Políticas (9) e Fundações (1).

\section{Gráfico 2 - Categorias das Entidades Coletivas Privadas}

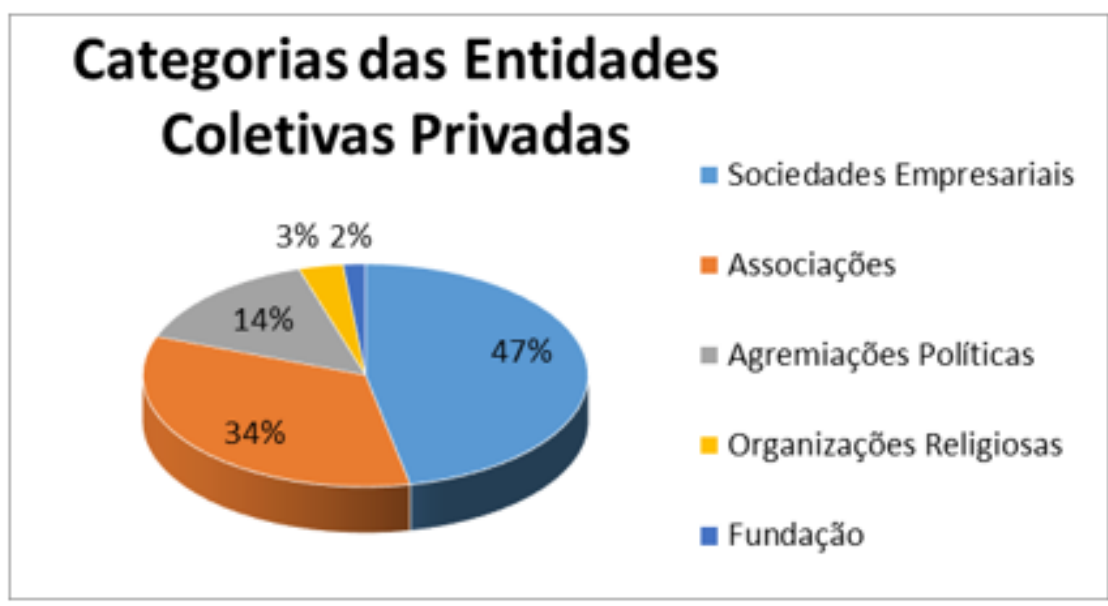

Fonte: Dados da pesquisa.

Ressaltamos que $47 \%$ são referentes a sociedades empresariais, isto é, que possuem "[...] acionistas ou são divididas em alíquotas" (PAZIN, 2005, p. 12). A seguir vêm associações, "[...] grupos que exercem atividade comum ou defendem interesses em comum" (PAZIN, 2012, p. 20) com 34\%. As agremiações políticas somam $14 \%$ e as organizações religiosas $3 \%$, regidas pela lei $\mathrm{n}^{\circ} 10.825$, de 22 de dezembro de 2003. E fundação, é a "pessoa jurídica autônoma destinada a fins de utilidade pública ou beneficência, mediante dotação especial de bens livres" (PAZIN, 2005, p. 11) e representa $2 \%$.

Na perspectiva de Bellotto (2006) e Marquant (1960), os arquivos de entidades coletivas privadas seriam classificados, em sua maioria, como arquivos sociais (53\%) e como arquivos econômicos (47\%). Seria possível discutir tal afirmação, embora não o façamos aqui.

Quanto aos acervos, os gêneros documentais, encontrados nestes arquivos são bem diversificados: textual, bibliográfico, cartográfico, iconográfico, sonoro, filmográfico e tridimensional, e as datas-limite do período de produção dos 62 arquivos varia entre 1563 a 2007.

A forma de entrada dos arquivos de entidades coletivas privadas nas instituições de memória é diversificada. 


\section{Gráfico 3 - Forma de Entrada dos Arquivos das Entidades Coletivas Privadas}

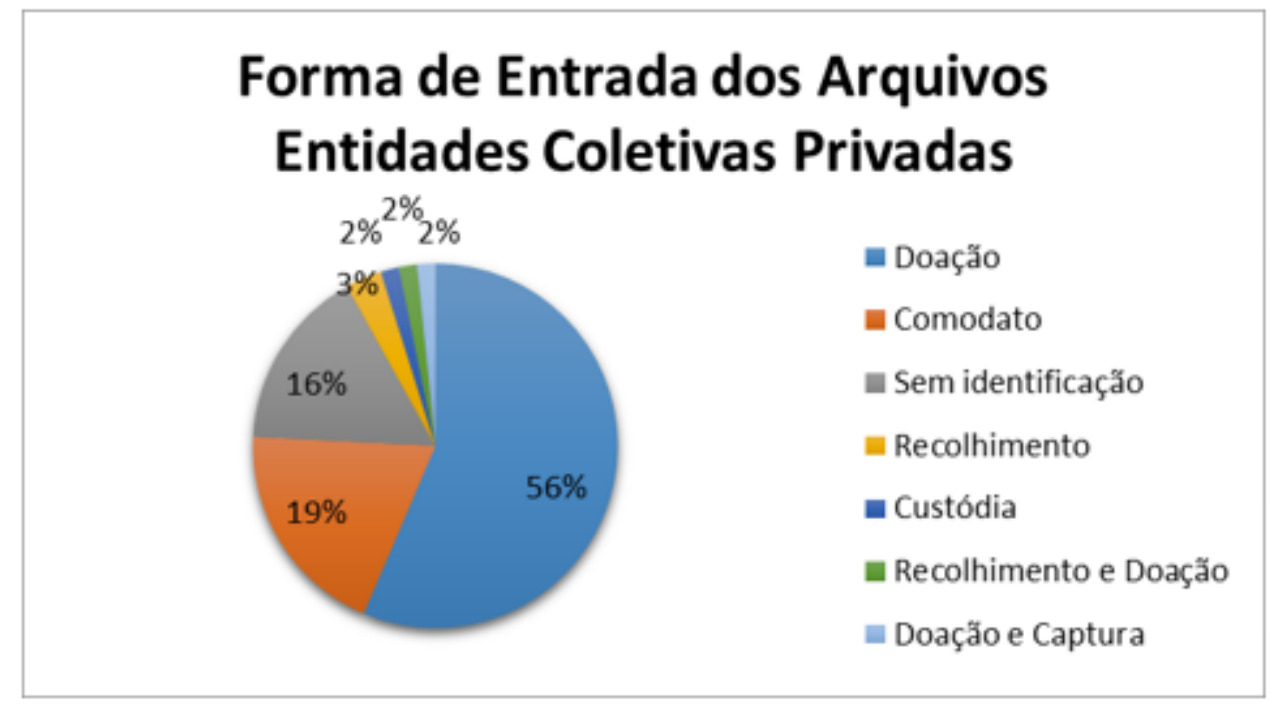

Fonte: Dados da pesquisa.

A doação é forma de entrada mais comum (56\%), e abrange um número maior do que o da soma de todas as demais categorias. Nenhum dos arquivos de entidades coletivas privadas teve sua entrada por meio de compra, como acontece com arquivos pessoais.

Considerando que as sete entidades custodiadoras somam um total de 1737 arquivos, apenas 62, ou seja, 4\% (do total de acervo) é de arquivos de entidades coletivas privadas. O gráfico 4 mostra a disparidade entre o total de fundos analisados e percentual de arquivos de entidades coletivas privadas.

Gráfico 4 - Total de Fundos x Arquivos das Entidades Coletivas Privadas

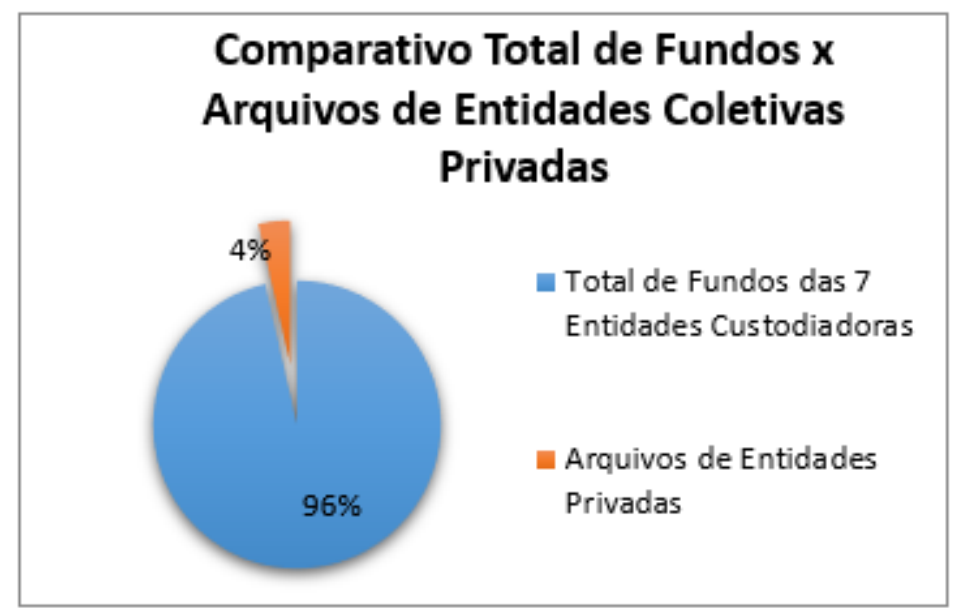

Fonte: Dados da pesquisa. 
Os instrumentos de pesquisa online das entidades custodiadoras de acervos arquivísticos, assim como seus websites, foram importantes ferramentas para obtenção de informações. Através dos sites institucionais, percebemos ainda que algumas das entidades custodiadoras cariocas, como o Arquivo Nacional e a Fundação Biblioteca Nacional, fazem parte do Programa Memória do Mundo da UNESCO, criado em 1992 com "[...] objetivo estimular a preservação e a ampla difusão de acervos" reconhecidos pelas comissões nacionais e internacionais, com o intuito de "despertar a consciência coletiva para o patrimônio documental da humanidade." A importância dos conjuntos documentais privados para o referido programa no Brasil pode ser avaliada pela presença obrigatória de um especialista sobre esses acervos no comitê nacional. Isto, não só é de grande valia para o patrimônio documental e a memória brasileira, como para todo o mundo.

Cabe registrar que nem sempre foi fácil comparar os dados, porque a forma de apresentá-los e até mesmo os critérios para as afirmações são diferentes e nem sempre claramente expostos pelas entidades custodiadoras.

\section{CONCLUSÃO}

Vislumbramos, por meio deste trabalho, que os conjuntos documentais das 62 entidades coletivas privadas, apesar de serem em ínfima quantidade, comparados aos novecentos arquivos pessoais, são de grande valia para conhecimento de um pouco da história de nossa sociedade. Melhor dizendo, a história destas entidades, traz informações sobre a economia e a indústria, os avanços tecnológicos, o campo social, a saúde, a política, a cultura e a religião, enfim, a realidade do país num determinado período. Muito sobre nossa trajetória pode ter sido perdido, por não ter havido uma preocupação com este tipo de documentação e de arquivo.

Ao longo dos anos e da história dos arquivos no Brasil, a atenção foi exclusivamente para os arquivos públicos e as leis foram pensadas para os mesmos. O cuidado com os arquivos privados ficou no campo dos arquivos pessoais, com a guarda e a preservação dos arquivos de políticos, dos 
literatos, dos cientistas, dos artistas, entre outros, ou seja, pessoas que foram importantes numa certa época e "mereceram" ter seus documentos guardados para posteridade, dos quais alguns foram considerados de "interesses público e social".

Não houve preocupação com a memória das atividades econômicas, com as sociedades empresariais, as associações, clubes, sindicatos, hospitais, instituições de ensino e centenas de outros tipos de entidades coletivas privadas. Talvez isso tenha ocorrido por não haver uma legislação ou uma política de conscientização e de preservação dos arquivos de entidades coletivas privadas, mostrando a importância destes arquivos para entendimento da história da nossa sociedade. Infelizmente, não parece ter existido nunca pelas entidades custodiadoras cariocas uma política de aquisição de arquivos das entidades coletivas privadas. Seria importante que isso fosse alterado.

A vida é feita de relações, e os arquivos também possuem as suas. Portanto voltar-se a atenção exclusivamente para um lado, isto é, para guarda dos arquivos públicos, como únicos instrumentos de memória, é não atentar para o outro lado, a memória nas entidades coletivas privadas, bem como as relações que os arquivos públicos têm com os arquivos privados.

Os arquivos pessoais ocupam um espaço dentro das entidades de memória, pois seus produtores ou familiares procuram doar seus arquivos, ou seja, tentam torná-los "públicos" de alguma forma, a fim de serem monumentos que retratem seus produtores e doadores. Por parte das entidades custodiadoras, também há uma tradição e, às vezes, até uma política de aquisição desses conjuntos, enquanto os arquivos de entidade coletiva privada não possuem o "seu lugar" nas entidades que visam à sua guarda e preservação, perfazendo apenas $4 \%$ do total do acervo custodiado. Obviamente, o fato de não serem contemplados nas políticas de aquisição de acervos das entidades custodiadoras contribui para que caiam no esquecimento social.

Uma parte da nossa história fica comprometida por não haver uma preocupação e uma política de preservação desta memória documental. Apesar de ser impossível guardar tudo que é produzido em nossa sociedade, 
soluções devem ser buscadas, tanto em termos de políticas públicas que estimulem a guarda desses acervos quanto de políticas institucionais das entidades custodiadoras para a aquisição de arquivos desse tipo. Tais conjuntos documentais são extremamente importantes e devem ser encarados como fazendo também parte do patrimônio nacional.

\section{REFERÊNCIAS}

ARQUIVO NACIONAL. Dicionário Brasileiro de Terminologia Arquivística. Rio de Janeiro: Arquivo Nacional, 2005. 232 p.

ASSOCIAÇÃO DOS ARQUIVISTAS HOLANDESES. Manual de arranjo e descrição de arquivos. Rio de Janeiro: Arquivo Nacional, 1973.

BASTOS, A. W. A ordem jurídica e os documentos de pesquisa no Brasilnotas de um documento preliminar. Arquivos do Ministério da Justiça, Brasília, v. 38, n. 159, p. 73-104, jul./set. 1981.

BASTOS, A. W. C.; ARAÚJO, R. C. de. A legislação e a política de arquivos no Brasil. Acervo, Rio de Janeiro, v. 5, n. 1, p. 19-33, jan./jun. 1990. Disponível em:

http://www.arquivonacional.gov.br/media/v.4,\%20n.2,\%20jul,\%20dez,\%201989v.5,n.1,jan,1990.pdf. Acesso em: 06 abr. 2018.

BELLOTTO, H. L. Problemática atual dos arquivos particulares. Arquivo \& Administração, Rio de Janeiro, v. 6, n. 1, p. 5-9, jan./abr. 1978.

BELLOTTO, H. L. Arquivo: estudos e reflexões. Belo Horizonte: Editora UFMG, 2014. 477 p.

BELLOTTO, H. L. Arquivos permanentes: tratamento documental. 4. ed. Rio de Janeiro: Fundação Getúlio Vargas, 2006. 320 p.

BRASIL. Constituição de 1988. Constituição da República Federativa do Brasil. Diário Oficial da União, seção 1, 5 out. 1988. Disponível em: http://www.planalto.gov.br/ccivil_03/constituicao/constituicao.htm. Acesso em: 06 abr. 2018.

BRASIL. Lei $n^{\circ} \mathbf{8 . 1 5 9}$, de 8 de janeiro de 1991. Dispõe sobre a política nacional de arquivos públicos e privados e dá outras providências. Diário Oficial [da] República Federativa do Brasil, Brasília, DF, 9. jan. 1991. Disponível em: http://www.planalto.gov.br/ccivil_03/leis/L8159.htm. Acesso em: 05 mar. 2018.

BRASIL. Lei $\mathbf{n}^{\circ} \mathbf{8 . 3 9 4}$, de 30 de dezembro de 1991. Dispõe sobre a preservação, organização e proteção dos acervos documentais privados dos presidentes da República e dá outras providências. Diário Oficial [da] República 
Federativa do Brasil, Brasília, DF, 30. dez. 1991. Disponível em: http://www.planalto.gov.br/ccivil_03/leis/L8394.htm. Acesso em: 04 abr. 2018.

CAMARGO, A. M. de A. Arquivos pessoais são arquivos. Revista do Arquivo público Mineiro, Belo Horizonte, v. 45, n. 2, p. 26-39, jul./dez. 2009. Disponível em: http://www.siaapm.cultura.mg.gov.br/acervo/rapm_pdf/2009-2-A02.pdf. Acesso em: 03 abr. 2018.

CAMARGO, C. Centros de documentação e pesquisa histórica: uma trajetória de três décadas. In: CPDOC 30 anos. Rio de Janeiro: Ed. Fundação Getulio Vargas/CPDOC, 2003. 192 p. Disponível em:

http://cpdoc.fgv.br/producao_intelectual/arq/1350.pdf. Acesso em: 03 abr. 2018.

CAMPOS, J. F. G. Apresentação. In: CAMPOS. J. F. G. (Org.). Arquivos Privados: abordagens múltiplas. São Paulo: ARQ-SP, 2016. 86 p.

CONSELHO NACIONAL DE ARQUIVOS (CONARQ). Resolução n 3, de 26 de Dezembro de 1995. Dispõe sobre o Programa de Assistência Técnica do Conselho Nacional de Arquivos. Disponível em:

http://www.conarq.arquivonacional.gov.br/legislacao/resolucoes-do-conarq/45resolucao-n-3,-de-26-de-dezembro-de-1995.html. Acesso em: 06 abr. 2018.

CONSELHO NACIONAL DE ARQUIVOS (CONARQ). Resolução $\mathbf{n}^{\mathbf{0}} \mathbf{1 7}$, de 25 de Julho de 2003. Dispõe sobre os procedimentos relativos à declaração de interesse público e social de arquivos privados de pessoas físicas ou jurídicas que contenham documentos relevantes para a história, a cultura e o desenvolvimento nacional. Disponível em:

http://www.conarq.arquivonacional.gov.br/legislacao/resolucoes-do-conarq/525resolucao-17.html. Acesso em: 05 abr. 2018.

COOK, T. Arquivos pessoais e arquivos institucionais: para um entendimento arquivístico comum da formação da memória em um mundo pós-moderno.

Revista Estudos Históricos, Rio de Janeiro, v. 11, n. 21, p. 129-149, 1998. Disponível em: http://bibliotecadigital.fgv.br/ojs/index.php/reh/article/view/2062. Acesso em: 05 abr. 2018.

EASTWOOD, T.; MACNEIL, H. Correntes atuais do pensamento arquivístico. Belo Horizonte: Editora UFMG, 2017.

ESTEVÃO, S. N. de M.; FONSECA, V. M. M. da. A França e o Arquivo Nacional do Brasil. Acervo, Rio de Janeiro, v. 25, n. 1, p. 81-108, jan./jun. 2010. Disponível em: http://revista.arquivonacional.gov.br/index.php/revistaacervo/article/view/42/4. Acesso em: 06 abr. 2018.

HEYMANN, L. Q. Indivíduo, Memória e Resíduo Histórico: uma reflexão sobre arquivos pessoais e o caso Filinto Müller. Revista Estudos Históricos, Rio de Janeiro, v. 10, n. 19, p. 41-66, 1997. Disponível em: 
http://bibliotecadigital.fgv.br/ojs/index.php/reh/article/view/2041/1180. Acesso em: 05 abr. 2018.

HEYMANN, L. Q. O lugar do arquivo: a construção do legado de Darcy Ribeiro. Rio de Janeiro: Contra Capa/ FAPERJ, 2012. 238p.

INSTITUTO BRASILEIRO DE GEOGRAFIA E ESTATÍSTICA (IBGE). Classificação Nacional de Atividades Econômicas - CNAE. Disponível em: http://cnae.ibge.gov.br/. Acesso em: 06 abr. 2018.

LAFER, C. O público e o privado: suas configurações contemporâneas para a temática dos arquivos. In: SEMINÁRIO DOCUMENTOS PRIVADOS DE TITULARES DE CARGOS PÚBLICOS, 2004. Anais... São Paulo: Instituto Fernando Henrique Cardoso, 2005. p. 33-49.

MARQUANT, R. Os arquivos e as modernas pesquisas econômicas e sociais. Rio de Janeiro: Arquivo Nacional, 1960.

MOLINA, T. dos S. Arquivos privados e interesse público: caminhos da patrimonialização documental. Acervo, Rio de Janeiro, v. 26, n. 2, p. 160-174, jul./dez. 2013. Disponível em:

http://revista.arquivonacional.gov.br/index.php/revistaacervo/article/view/522.

Acesso em: 06 abr. 2018.

ORGANIZAÇÃO DAS NAÇÕES UNIDAS PARA A EDUCAÇÃO, A CIÊNCIA E A CULTURA (UNESCO). Programa Memória do Mundo (1992). Disponível em: http://www.unesco.org/new/pt/brasilia/communication-andinformation/access-to-knowledge/documentary-heritage/. Acesso em: 06 abr. 2018.

PAES, M. L. Arquivo: teoria e prática. Rio de Janeiro: Fundação Getúlio Vargas, 2004. 228p.

PAZIN, M. Arquivos de empresas: tipologia documental. São Paulo: Associação dos Arquivistas de São Paulo, 2005. 39 p.

PAZIN, M. Arquivos de organizações privadas: funções administrativas e tipos documentais. São Paulo: ARQ-SP, 2012.

ROUSSEAU, Jean-Yves; COUTURE, C. Os fundamentos da disciplina arquivística. Lisboa: Publicações Dom Quixote, 1998.

SCHELLENBERG, T. R. Arquivos Modernos: princípios e técnicas. 6. ed. Rio de Janeiro: FGV, 2006. 388 p.

VITORIANO, M. C. de C. P. A presença de fundos privados institucionais nos arquivos públicos estaduais do Brasil. In: CAMPOS. J. F. G. (Org.). Arquivos

Privados: abordagens múltiplas. São Paulo: ARQ-SP, 2016. p. 9-23. 
VITORIANO, M. C. de C. P. Acervos privados no Arquivo Público do Estado de São Paulo: uma visão sobre fundos institucionais. Revista do Arquivo, São Paulo, n. 4, p. 1-14, mar. 2017. Disponível em:

http://www.arquivoestado.sp.gov.br/revista_do_arquivo/04/artigo_07.php\#inicio _artigo. Acesso em: 06 abr. 2018.

\title{
THE PROFILES AND THE PLACE OF THE PRIVATE INSTITUTIONAL ARCHIVES IN ARCHIVAL CUSTODY ENTITIES OF THE CITY OF RIO DE JANEIRO
}

\begin{abstract}
Introduction: The absence of reflection in the archives area on private archives of corporate bodies imposes the study of "their place" in the current Brazilian context and in the entities that hold and preserve the national memory. Objective: To investigate the profile and the place of the private archives of corporate bodies in archival custody entities of the city of Rio de Janeiro. Methodology: Exploratory and descriptive research on the profile and "locus" place of these archives based on the institutions of Rio de Janeiro present in the Cadastro Nacional de Entidades Custodiadoras de Acervos Arquivísticos with websites and online guides, to quantify and identify the held private archives of corporate bodies. Results: Analysis of the held archives of private corporate bodies in face the number of personal private archives, the characteristics they have and their categorization in thematic terms and activities performed by their creators. Conclusions: Weak presence of archives of private corporate bodies in memory institutions in Rio de Janeiro, inexistence of acquisition policies for such collections and risk of serious gaps in national documentary heritage.
\end{abstract}

Descriptors: Private Archives. Private archives of corporate bodies. Permanent archive. Documentary heritage.

\section{PERFIL Y LUGAR DE LOS ARCHIVOS PRIVADOS INSTITUCIONALES EN ENTIDADES CUSTODIADORAS CARIOCAS}

\begin{abstract}
RESUMEN
Introducción: La ausencia de reflexión en el área archivística sobre archivos privados de entidades colectivas impone el estudio de su lugar en el actual contexto brasileño y en las entidades de custodia y preservación de la memoria nacional. Objetivo: Investigar el perfil y el lugar de los archivos privados de entidades colectivas en entidades custodiadoras de acervo archivístico de la ciudad de Río de Janeiro. Metodología: : Investigación exploratoria y descriptiva sobre el perfil y el lugar de esos archivos con base en las instituciones cariocas presentes en el Cadastro Nacional de Entidades Custodiadoras de Acervos Arquivísticos con sitios y guías online, para cuantificar e identificar los archivos privados de entidades colectivas custodiadas. Resultados: Análisis de los archivos de entidades colectivas privadas custodiadas frente al número de archivos privados personales, las características que poseen y su categorización en términos temáticos y de actividades realizadas por sus
\end{abstract}

Inf. Inf., Londrina, v. 24, n. 1, p. 383 - 402, jan./abr. 2019. 
productores. Conclusiones: Escasa presencia de archivos de entidades colectivas privadas en las instituciones de memoria cariocas, inexistencia de políticas de adquisición para ese tipo de acervos y riesgo de graves lagunas en el patrimonio documental nacional.

Descriptores: Archivos Privados. Archivos privados de entidades colectivas. Archivo permanente. Patrimonio documental. 